\title{
An Automated Hybrid Attendance Management System for Academic Sector
}

\author{
W. K. El Said \\ Dept. of Computer Science \\ Mansoura University, \\ Egypt
}

\author{
Hanan. E. Abdelkader \\ Dept. of Computer Science \\ Mansoura University, \\ Egypt
}

\begin{abstract}
The development of the educational system has always been the focus of attention of officials in different countries of the world. In the higher education sector of Egypt, developing faculty members abilities has become one of the most interesting aspects in the recent years. Several projects were presented to develop the abilities of faculty members in the Egyptian Universities, the most important of them was the "Faculty Leadership Development Project". So far, the faculty members attendance in the programs matrix of this project are taken by manual paper methods which have many weakness and drawbacks. Therefore, the current study proposed a hybrid system based on Radio Frequency Identification technology and Web services to automatically manage the members attendance process and print out the attendance report. The usability of the proposed system has been measured using the System Usability Scale questionnaire. The overall system usability scale score obtained from the test team was $91 \%$, indicating a high level of usability and system acceptance.
\end{abstract}

Keywords- Educational Sector; FLDP; Hybrid System; RFID; Web Technology; SUS Questionnaire.

\section{INTRODUCTION}

Over the past decades, teaching was the main component in educational sector. Therefore, all educational plans focused only on providing good teaching [1]. In response to technological breakthroughs, this view has changed dramatically to include other aspects in educational system for increasing productivity and facilitating various works [2].

Currently, educational institutions have adopted the use of Information and Communication Technologies to achieve more efficient and competitive system in delivering both, lectures and administrative processes [3].

By the 21th century, higher education in Egypt faced unprecedented challenges resulting from various factors, such as globalization, increasing knowledge value and revolution of information and communication technology. For these factors, Ministry of Higher Education (MOHE) in Egypt set a longterm plan for reforming various aspects of higher education. This plan included many reform projects, the most important of them is the Faculty and Leadership Development Project (FLDP) [4]

FLDP is the process of preparing and enhancing the productivity of academic staff for other pertinent roles, such as teaching, assessment, research, administrative issues as well as the development of resource material and facilitation which are required for both active and student centered learning [5].

The main purpose of FLDP is to provide the faculty members with a training matrix containing a number of development projects to enable them to cope with developments of the era, to face competitiveness, and to increase the efficiency of higher education outcomes [6].

To encourage the faculty members to attend those development programs, they have been linked to the promotion of higher academic and functional degrees [4], where each scientific degree (Master - PhD - Assistant Professor - Professor) requires six development programs according to the decision of the Supreme Council of Egyptian Universities in its session No.439 in 23/3/2006 [7].

Up until now, FLDP attendance records have been managed manually by having faculty members sign beside their names on attendance sheet during the period of the training program. Unfortunately, such traditional method is out-dated and lacks automation that causes a number of troubles, such as [8]:

- It takes a long time, as each faculty member should be to find and sign their names on the printed attendance sheet.

- It allows faculty member to sign for another faculty member's name whether mistakenly or intentionally.

- It causes a great boredom and annoyance for both trainee and trainer.

- It exposes the attendance sheet for damage, alteration or misuse.

In the current digital era, having an automated system to solve these troubles becomes an urgent demand. Therefore, the main purpose of this study is to propose a hybrid automated system based on Radio Frequency Identification technology and Web application as a solution for managing the process of registering the academic staff's attendance in FLDP in Mansoura university in Egypt.

The remainder of the paper structures as follows: Section II describes the basic tool used in this research work. Section III defines the research problem. Section IV provides the all details of the proposed system. Section V evaluates the proposed system efficiency. Finally, the conclusions and future directions for this work are presented in the last section.

\section{RADIO FREQUENCY IDENTIFICATION}

Historically, the initial attempts to transmit information without wires back to World War II in 1935 by Scottish physicist Sir Robert Alexander Watson-Watt. In that year, Sir Robert invented a radar to detect and sense aircraft at a long distance of miles. The weakness of this method lies in its inability to distinguish between enemy aircraft and friendly/allied aircraft. Thereafter, earnest attempts to discover another advanced methods for object identification continued. 
In the early 1970s, these efforts succeeded in reaching an effective method called Radio Frequency Identification (RFID) technology [9].

RFID refers to wireless technology that uses radio waves to automatically identify items within a certain proximity [10]. Technologically, RFID belong to the family of Barcoding but the first method outperforms the last method in many aspects as shown in the following [11]:

- Barcode labels require a clear line of sight to be read; while a sight line is not required to read RFID tags.

- Barcode labels are read individually, one after another; while multiple RFID tags can be read together by the reader.

- Barcode labels cannot be read in damaged or dirty environments; while the damaged or dirty environments cannot affect RFID tags.

- Barcode labels can only identify the type of item; while a unique or specific item can be identified by RFID tags.

- Barcode labels cannot be updated; while information of RFID tags can be modified and updated.

- Barcode labels are vulnerable to human error resulting from human manual tracking; while RFID tags are tracked automatically, thus they are error free.

The RFID system consists of various components which are integrated with each other to perform the required tasks $[12,13]$.The main elements shared between any RFID system are [14]: Element-1; is the tag (transponder), which contains the information or a part of it. Element-2; is the reader (interrogator and its integrated or separated antenna), which emits a radio signal at a fixed frequency to power up the tag and communicates with it using the backscattering approach. Element-3; is the software application, which is often based on a database of varying sizes and complexities according to the processed data and the security restrictions.

RFID systems can be classified into two main types.Type1 ; is active tag which includes a power source and has long communications range, but the cost is high. Type-2; is passive tag which does not have a power source and the cost is low, but the communications range is short $[15,16$, $17,18,19]$

Generally, the application of RFID technology is concentrated in three basic areas: monitoring the system state, tracking the persons/objects and supervising the behaviors, activities, or other changing information. Lately, the scope of its application has increased to include many fields of life such as [20]: logistics and supply, manufacturing, agriculture management, health care and medicine, marine terminal operation, military and defense, payment transactions, environment monitor and disaster warning, transportation, retailing and warehousing and distribution systems, ... etc.

\section{PROBLEM DEFINITION}

For decades, the focus of educational institutions has been limited to just one element of educational system, which is "Students Learning". This deficient view has changed dramatically with the recent changes to focus on other elements of educational system. As faculty members play an important role in higher education institutions, they have become one of the most important aspects of concern in the university sector.

The strategies of modernization of Egyptian higher education are based on the development of faculty members' abilities not only on the academic level but also include both the administrative and leadership levels. This trend is achieved by providing them with a number of training programs in various areas of the life, and these programs are briefly called "FLDP".

On hand, a large number of participants in the development programs reported their satisfaction with FLDP as these programs provide them an opportunity to exchange their views, ideas and experiences with other faculty members in various faculties. On the other hand, registering attendance of faculty members in the FDLP until now is performed by paper based methods that have several flaws for example, lack of accuracy, lack of credibility, require a great effort, take a long time, cause large distractions in training classroom, ... etc.

To avoid the cons of manual methods of recording faculty members attendance in development projects, the current study provides an automatic hybrid system based on both RFID technology and Web services.

\section{PROPOSED SYSTEM}

This section of the paper describes the details of the proposed system including components, architecture, development scenarios and evaluation process

\section{A. System Components}

The proposed RFID system comprises of two parts as shown in Fig.1.The first one is being the hardware components and the second is the software components.

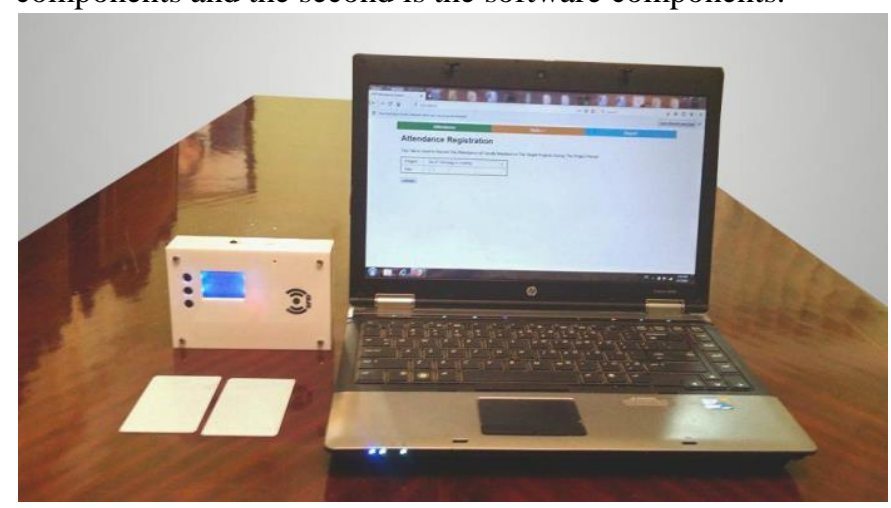

Fig 1: Components of proposed system

In the following sub-sections, we will review these two parts in more detail:

\section{1) Hardware Components}

It is known, hardware is the physical devices that can be either seen or touched. The hardware components used in the proposed system can be divided into two parts. Part-1; is an RFID tag contains a unique secret information that is read via radio waves. Part-2; is an electronic device contains several components that are integrated with each other to communicate with RFID tag to achieve the objectives of the system. A detailed description of these hardware devices is provided below: 


\section{- RFID Tag}

This component used to electronically store the information of the academic staff members. The supported tag by our system is a MiFare Classic (13.56MHz RFID/NFC) white passive card.

\section{- Electronic Device}

This component used to achieve communication with the passive RFID tag and to operate its contents. The external design of this electronic device is made from acrylic plastic material with white color. While, its internal design includes the following components:

\section{i. $\quad$ RFID Reader Module}

This portion is an electronic remote data reading module that contains a built-in resonant antenna that is directly connected to a silicon chip. It uses radio frequency waves to send power, to transmit signals for activating the RFID tag. Once the activation occurs, the waves signals are returned again with the unique data stored on the RFID tag and transmits it serially to the microcontroller.

\section{ii. Microcontroller Module}

This portion is an embedded module that contains many integrated components such as processor, memory, database developed in $\mathrm{C}++$, local server developed in $\mathrm{C}++, \ldots$ etc. In addition, it supports Wi-Fi network connection by using ESP12E Wi-Fi Module. It reads the data of the RFID tag and matches it with that stored in the database. If a valid authentication occurs, the faculty member attendance is registered in the database of the microcontroller.

\section{iii. Graphical LCD (Liquid Crystal Display)}

This portion includes a Nokia 5110 LCD display, that inexpensive, easy to use, consumes low power, small size and readable.

\section{iv. Power Button}

This portion includes a power button used to turn on the electronic device.

\section{v. Control Buttons}

This portion includes three buttons (Up, Down, Select) to control the processes performed by the electronic device.

\section{vi. Battery}

This portion includes a dynamic rechargeable Li-ion Lithium Battery $(3.7 \mathrm{~V}, 1500 \mathrm{mAH})$, that supplies power to the components of the electronic device.

\section{vii. Charger Circuit}

This portion includes a Li-ion Lithium Battery charging module (TP4056), that can recharge the battery when its power gets low.

\section{2) Software Component}

It is known that, software includes both programs and data, and it is defined as the intangible components that manage the hardware resources by directing the target works to the electronic devices. In current work to handle the tag information and control the readers, a Web-based application has been built using HTML, CSS, and JavaScript.

\section{B. System Architecture}

The proposed system has been designed as a client-server model. At first, the RFID reader is connected to the client computer using a Wi-Fi mode. Once the instructor presses the "Power Button" of the electronic device, the RFID reader is on and senses its field of operation. Whenever an RFID tag enters its neighborhood, it sends an electromagnetic wave to the
RFID tag. The RFID tag reflects back the wave along with its unique data. The Web based application for taking attendance is run. The project instructor needs to authenticate himself by logging into the system. If the response is positive, the instructor is redirected to the "Attendance Tab" where he needs to select the project name for which he wants to take attendance. After the project name is validated by using database, the RFID tags are read and the members attendance are enrolled in the database to be used later, especially in the reporting phase. A general block diagram for client side architecture is shown in Fig.2.

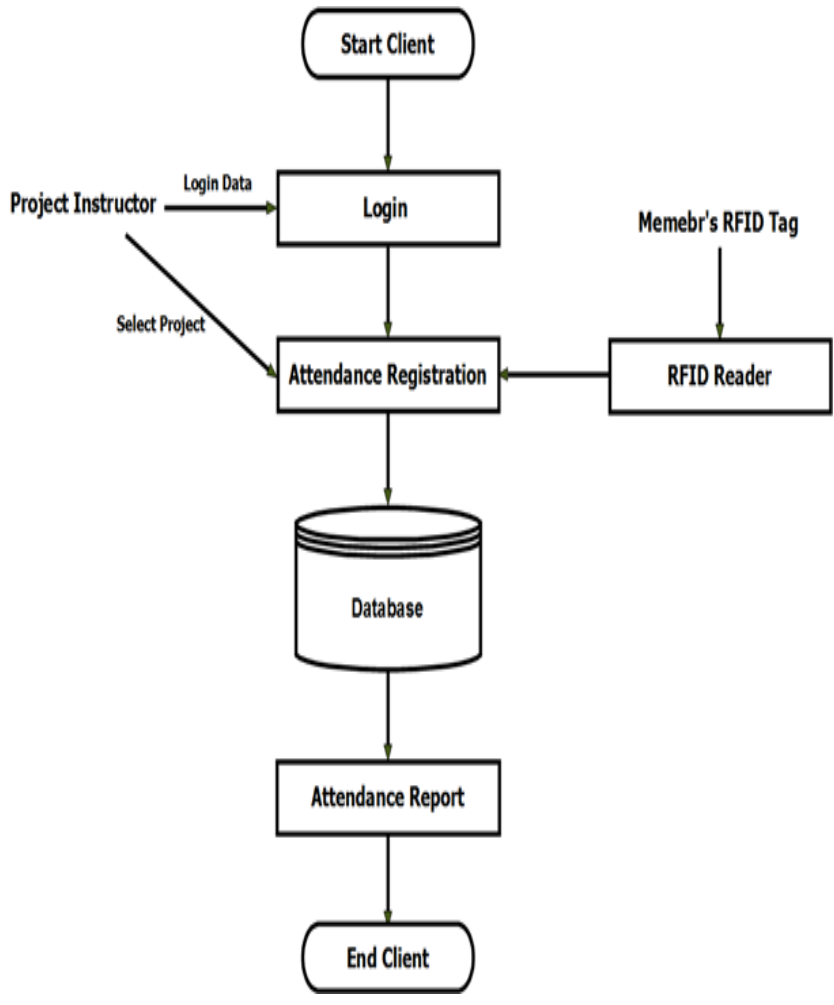

Fig 2: Block diagram showing client side architecture

On the other hand, the server fetches and retrieves data needed -like project name and enrolled members- from database. The web portal in turn queries the server database and retrieves data required. Finally the web portal responds to the user as requested. A general block diagram for server side architecture is shown in Fig.3.

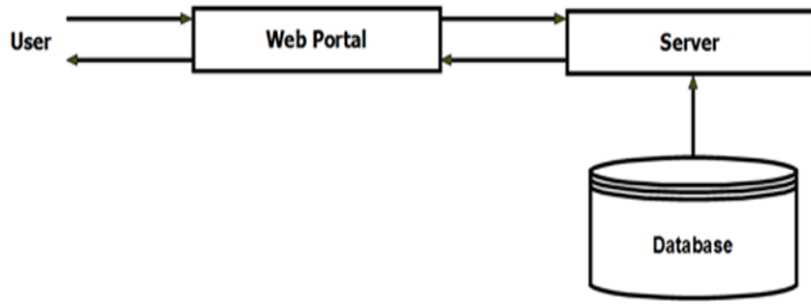

Fig 3: Block diagram showing server side architecture

\section{System Development}

The homepage of proposed website is generally divided into three tabs: Attendance, Tools, Report. A sample screenshot of the proposed system is shown in Figs 4:8. 


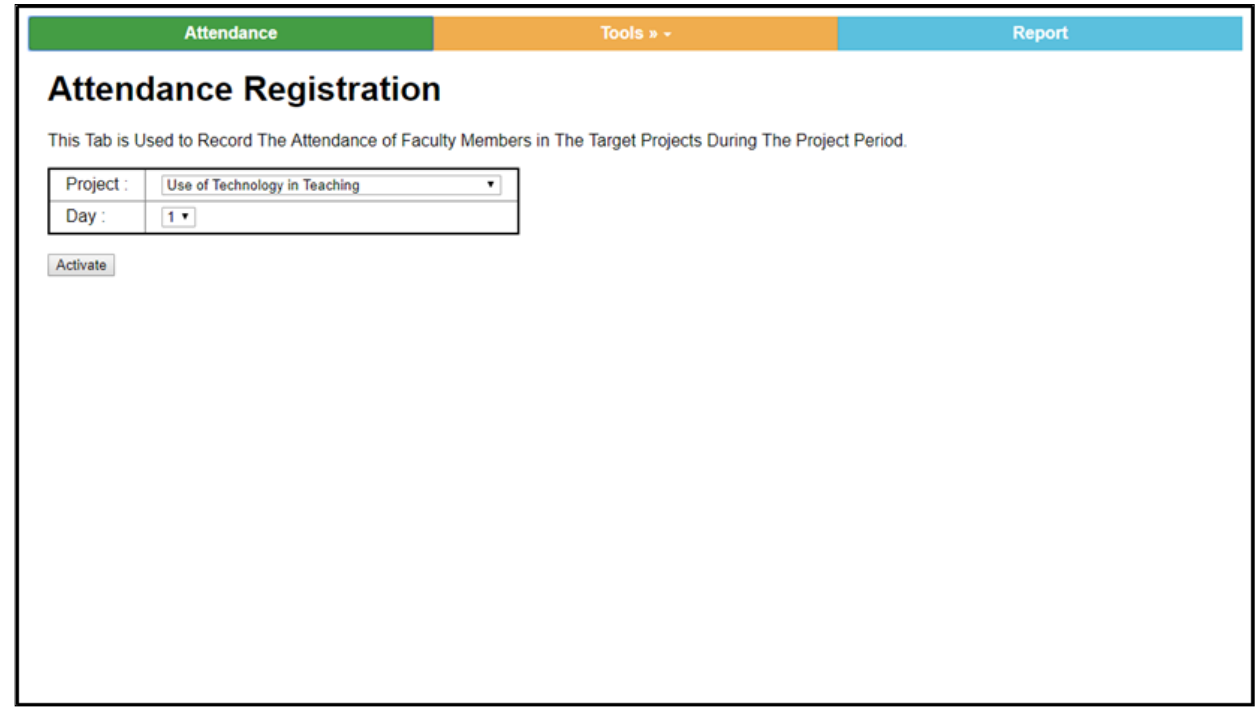

Fig 4: Window of registering members' attendance in target FLDP

\begin{tabular}{|c|c|c|c|c|}
\hline \multicolumn{4}{|c|}{ Attendance } & Report \\
\hline \multicolumn{5}{|c|}{ Manage Projects } \\
\hline \multicolumn{5}{|c|}{$\begin{array}{l}\text { This Tab is Used to Add New Training Project to The System as well as to Register The Faculty Members in The Target Training } \\
\text { Projects. }\end{array}$} \\
\hline Project ID & $\begin{array}{l}\text { Project Name } \\
\end{array}$ & Delete & Manage & \\
\hline 1 & Use of Technology in Teaching & Desele & Manage & \\
\hline 2 & Adopted Hours Systems & Detele & Manage & \\
\hline 3 & Examination System and Evaluating Students & Desete & Manase & \\
\hline 4 & Quality Standards in Teaching Process & Detele & Manage & \\
\hline 5 & Scientific Publication & Desele & Mamage & \\
\hline 6 & Management of the Research Team & Detele & Manage & \\
\hline 7 & Intellectual Property in the Research & Detele & Mmase & \\
\hline 8 & Ethics of Scientific Research & Deselete & Manage & \\
\hline 9 & Strategic Planning & Detele & manage & \\
\hline 10 & Academic Administration & Develete & Manage & \\
\hline 11 & Financial Aspects and Legal Acts in University & Develo & Mmage & \\
\hline 12 & Time Management and Meetings & Desele & Manage & \\
\hline 13 & Communication Skills in the Patterns of Education & Deseloto & Mmase & \\
\hline 14 & Effective Presentation & Detele & manage & \\
\hline 15 & Organization of Scientific Conferences & Deselo & Manage & \\
\hline 16 & Professional Behavior & Detele & Manase & \\
\hline
\end{tabular}

Fig 5: Window of managing FLDP matrix

\begin{tabular}{|c|c|c|c|c|}
\hline \multicolumn{3}{|c|}{ Attendance } & Tools n. & Report \\
\hline \multicolumn{5}{|c|}{ Manage Cards } \\
\hline \multicolumn{5}{|c|}{$\begin{array}{l}\text { This Tab is Used to Register The Faculty Members Data on The Cards to be Later Used in The Members Attendance } \\
\text { Registration Process. }\end{array}$} \\
\hline Card Status: & \multicolumn{2}{|c|}{ Not Present } & & \\
\hline \multicolumn{5}{|l|}{ Card UID: } \\
\hline \multicolumn{5}{|l|}{ Database ID: } \\
\hline \multicolumn{5}{|l|}{ Member Name: } \\
\hline \multicolumn{5}{|c|}{\begin{tabular}{|l|l|} 
Edit Delete \\
D.
\end{tabular}} \\
\hline Member Name & Database ID & UID & & \\
\hline Ahmed & 1 & BDF1BA39 & & \\
\hline Amr & 2 & 6CEB1FC9 & & \\
\hline Mohamed & 3 & 393BDFDB & & \\
\hline Hamada & 4 & CE348E7B & & \\
\hline Youssef & 5 & A05DB939 & & \\
\hline
\end{tabular}

Fig 6: Window of managing RFID tags 


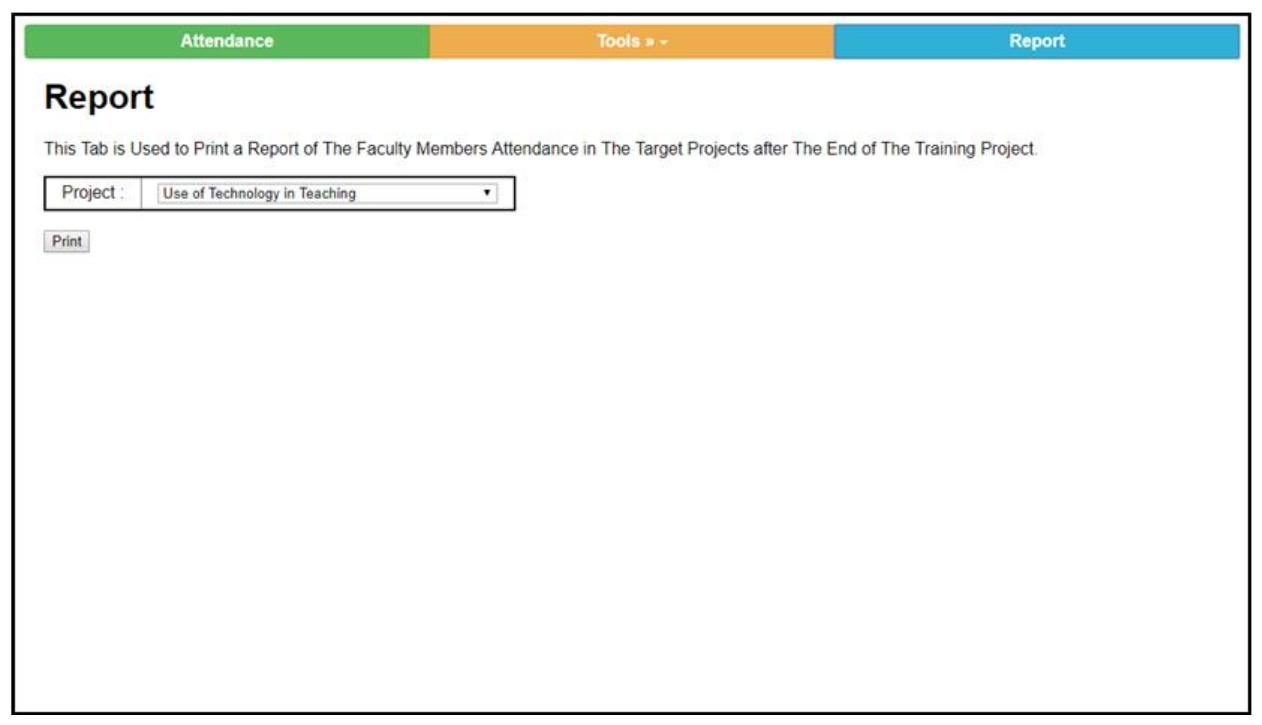

Fig 7: Window of first stage of printing attendance report

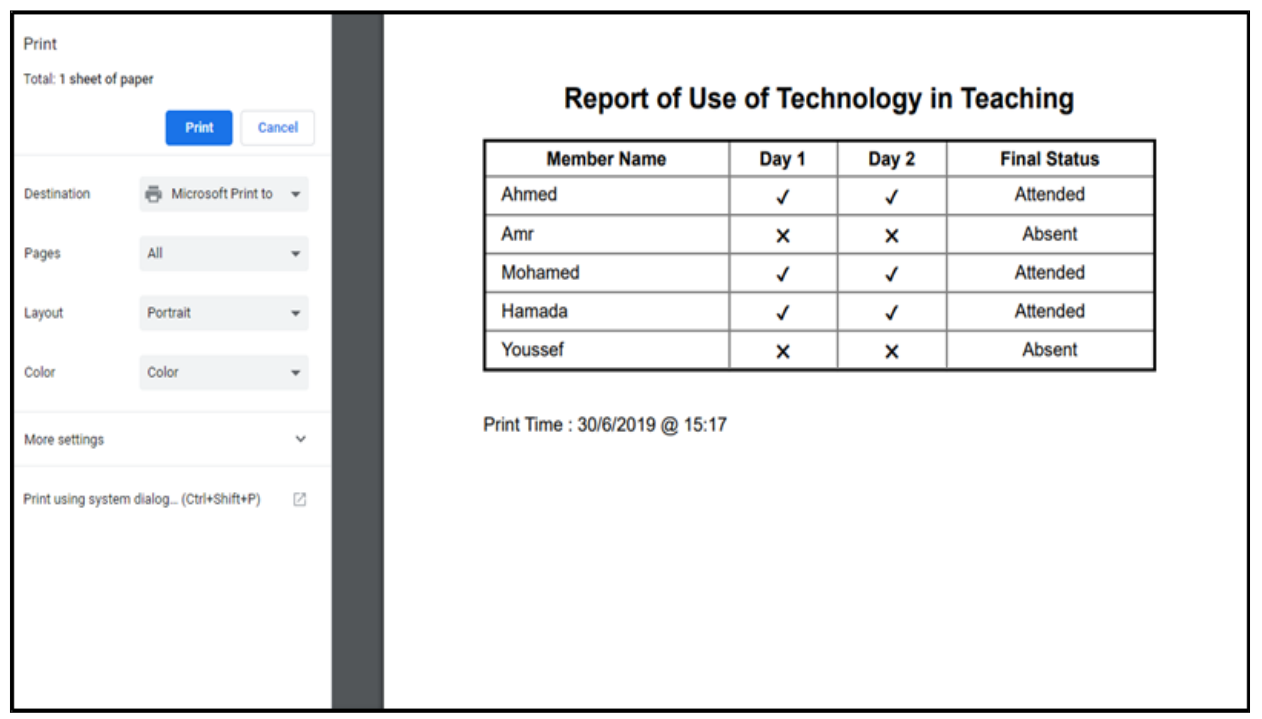

Fig 8: Window of final stage of printing attendance report

\section{SYSTEM TESTING \& EVALUATION}

The effectiveness of the proposed system to manage the faculty members attendance in FLDP has been evaluated by using usability testing approach which mainly aims to measure the degree or extent to which the software product achieves its pre-set intended objectives. The evaluation process of the current system has focused on the following aspects:

- Accuracy: Does the proposed system recognize the faculty members and register their attendance in the FLDP correctly?

- Efficiency: What the amount of time does the proposed system consume to complete all the required tasks?

- Simplicity: Does the system user communicate with the proposed system easily?

This experimental evaluation has been performed by a group of end users from Mansoura University who represent a part of the target audience. The usefulness of the proposed system has been captured based on the feedback obtained from participant team who filled the System Usability Scale (SUS) questionnaire after testing the proposed system.

In fact, the original SUS questionnaire has been adopted due to its reliability, simplicity, speed, cheap price and ease of use to the participants of this evaluation. The statements of the original SUS items has been slightly modified to match the current study. The questionnaire used in this experimental study consists of 10 questions exploring the functions of the system and has been presented to the evaluators.

For each question in the used SUS questionnaire, the participant selects a score point from 1-5, where point (1) means Strongly Disagree, point (2) means Disagree, point (3) means Neither Agree Nor Disagree, point (4) means Agree and point (5) means Strongly Agree. Fortunately, all the provided questionnaires were completed as required and were returned for statistical analysis. To calculate the total SUS score of each questionnaire filled by the participants, we 
depended on the rule presented in [21], which includes the following steps:

- For questions with numbers 1, 3, 5, 7, and 9: we have subtracted (1) form user's response scale value.

- For questions with numbers 2, 4, 6, 8, and 10: we have subtracted user's response scale value from (5).

- We have multiplied the sum of user's scores by (2.5) to obtain the SUS score in range 0 to 100.

The SUS scores obtained from surrogate users involved in the system evaluation process is summarized below in Table I.

TABLE I. $\quad$ EXPREMINTAL EVALUATION RESULT
\begin{tabular}{|c|c|}
\hline Evaluator & SUS Score [\%] \\
\hline EVAL1 & 78 \\
\hline EVAL2 & 90 \\
\hline EVAL3 & 92 \\
\hline EVAL4 & 98 \\
\hline EVAL5 & 85 \\
\hline EVAL6 & 94 \\
\hline EVAL7 & 98 \\
\hline EVAL8 & 96 \\
\hline EVAL9 & 82 \\
\hline EVAL10 & 97 \\
\hline Overall Average [\%] & $\mathbf{9 1}$ \\
\hline
\end{tabular}

The previous results indicated that, four evaluators rated the system overall performance greater than or equal to $95 \%$, three evaluators rated the system overall performance greater than or equal to $90 \%$, two evaluators rated the system overall performance greater than or equal to $80 \%$, and one evaluator rated the system overall performance greater than or equal to $70 \%$. These results also showed that, the mean SUS score of all surrogate users participating in the experiment was $91 \%$.

According to the [22], the obtained SUS score is classified as over average usability, while it is classified as excellent usability according to [23], whereas according to the SUS scores classification in [24] it is classified as best imaginable usability.

From these superior results, we conclude that the proposed system is an effective tool that can be applied on a wider range in different universities of Egypt to register the attendance of faculty members in the FLDP, not just Mansoura University where the researchers work.

\section{CONLUSION}

By using sensing identification devices, the attendance registration process in educational institutions has become easier and more reliable. The current study has employed RFID technology and Web services to create a Hybrid system to automatically register the attendance of faculty members in the FLDP in Mansoura University. The performance of the new system has been tested by a number of Mansoura University faculty members using SUS questionnaire. The obtained evaluation results were indicated that, the new system achieved distinctive levels of usability, making it a useful tool for the University Development Center in Mansoura university.

\section{REFERENCES}

[1] Bidabadi,N.S., Isfahani,A.N., Rouhollahi,A., \& Khalili,R., "Effective teaching methods in higher education: requirements and barriers", Journal of Advances in Medical Education \& Professionalism, vol.4, no.4, p.170, 2016.

[2] Mati,Jr., Edmund,O., Muji,M.M.F., \& Quintela,Y.M.P., "Faculty attendance monitoring using rfid with overload computation and email notification for city college of calamba", Bachelo Dissertation, City College of Calamba, 2017.

[3] Al-Shezawi,M.O., Yousif,J.H., \& AL-Balushi,I.A., "Automatic attendance registration system based mobile cloud computing", International Journal of Computation and Applied Sciences IJOCAAS, vol.2, Issue. 3, 2017.

[4] "Higher education in Egypt country review report", Available at http://s3.amazonaws.com/zanran_storage/mhespu.org/ContentPages/2473387763.pdf

[5] Abdulghani, H.M., Ahmad, F., Irshad, M., Khalil, M.S., AlShaikh, G.K., Syed, S., \& ... Haque, S., "Faculty development programs improve the quality of Multiple Choice Questions items' writing", Scientific Reports, 2015.

[6] Lamine, B.,"Towards an Arab higher education space: international challenges and societal responsibilities", Proceedings of The Arab Regional Conference on Higher Education, UNESCO, 2010

[7] http://udc.mans.edu.eg/fldp/arabic/

[8] ElSaid, W.K., "A system for managing attendance of academic staff members in university development programs using face recognition", International Journal of Intelligent Computing and Information Sciences, vol.17, no.4, 2017.

[9] Mahyidin.M.F.B., "Student attendance using RFID system", Bachelor Dissertation, Universiti Malaysia Pahang, 2008.

[10] Darcy, P., Pupunwiwat, P., \& Stantic, B., "The challenges and issues facing the deployment of RFID technology", In Deploying RFID-Challenges, Solutions, and Open Issues. IntechOpen, 2011.

[11] White.G.R.T, Gardiner.G, Prabhakar.G., \& Abd Razak.A., "A comparison of barcoding and RFID technologies in practice", Journal of Information, Information Technology, and Organizations, vol.2, pp.119-132, 2007.

[12] Ahsan, K., Shah, H., \& Kingston, P., "RFID applications: an introductory and exploratory study". IJCSI International Journa of Computer Science Issues, vol.7, issue.1, no.3, pp.1-7, 2010.

[13] Ajami, S., \& Rajabzadeh, A., "Radio Frequency Identification (RFID) technology and patient safety", Journal of Research in Medical Sciences : The Official Journal of Isfahan University of Medical Sciences, vol.18, no.9, pp. 809-813, 2013.

[14] Tedjini, S., \& Perret, E., "Radio-Frequency Identification systems and advances in tag design", URSI Radio Science Bulletin, no.331, pp.9-20, 2009

[15] Kinoshita, S., Ohkubo, M., Hoshino, F., Morohashi, G., Shionoiri O., \& Kanai, A., "Privacy enhanced active RFID tag", Cognitive Science Research Paper-University of Sussex CSRP, no.577, p.100, 2005

[16] Jian, M.S., \& Wu, J.S., "RFID applications and challenges. in Radio Frequency Identification from system to applications", IntechOpen, 2013.

[17] Jechlitschek, C., "A survey paper on Radio Frequency Identification (RFID) trends", Available at: https://www.researchgate.net/publication/228573858_A_survey_ paper_on_Radio_Frequency_Identification_RFID_trends.

[18] Xunxun, W., "Design of passive UHF RFID tag antennas and industry application”, Master Thesis, University of Gävle, 2010.

[19] González, G.Z.,"Radio Frequency Identification (RFID) tags and reader antennas based on conjugate matching and metamaterial concepts", Doctoral Dissertation, Universitat Autònoma De Barcelona, 2013

[20] Jia, X., Feng, Q., Fan, T., \& Lei, Q., "RFID technology and its applications in Internet of Things (IoT)", In 2012 2nd International Conference on Consumer Electronics, Communications and Networks (CECNet), IEEE, pp.1282-1285, 2012. 
[21] Martins, A.I., Rosa, A.F., Queirós, A.,Silva, A., \& Rocha, N.P., "European portuguese validation of the System Usability Scale (SUS)", Procedia Computer Science, no.67, pp.293-300, 2015.

[22] Tullis, T.S., \& Stetson, J.N., "A comparison of questionnaires for assessing website usability", In Usability Professional Association Conference, vol.1, 2004.

[23] Bangor, A., Kortum, P., \& Miller,J., "Determining what individual SUS scores mean: adding an adjective rating scale", Journal of Usability Studies, vol.4, no.3, pp.114-123, 2004.

[24] Kurosu,M., "Human-computer interaction. interaction contexts", Part II. Ed, 19th International Conference, HCI International 2017, Vancouver, BC, Canada, 2017. 